Case Study

\title{
Effect of the release exercise and exercise position in a patient with carpal tunnel syndrome
}

\author{
WON-GYU YOO ${ }^{1)}$ \\ 1) Department of Physical Therapy, College of Biomedical Science and Engineering, Inje University: \\ 607 Obangdong, Gimhae, Gyeongsangnam-do 621-749, Republic of Korea
}

\begin{abstract}
Purpose] This study examined the effect of the release exercise and exercise position in carpal tunnel syndrome (CTS). [Subject] A 40-year-old, right-hand-dominant man presented with CTS, with pain and progressive tingling and numbness in the right hand. [Methods] The subject performed three exercises: (1) release, (2) wrist flexor stretching, and (3) wrist extensor stretching. In session 1, the subject performed exercises 2 and 3 in the standing position for 2 weeks. In session 2, the subject performed all three exercises in the supine position for 2 weeks. [Results] The pressure pain threshold decreased after session 1 and decreased further after session 2, and the Phalen's test and Tinel sign became progressively less positive. [Conclusion] Exercises in the supine position, including release exercises, are recommended for CTS.

Key words: Carpal tunnel syndrome, Exercise, Wrist stretching
\end{abstract}

(This article was submitted Jun. 18, 2015, and was accepted Jul. 23, 2015)

\section{INTRODUCTION}

The carpal tunnel is an anatomical passageway bounded dorsally and laterally by the hemicircular carpal bones, and on the palmar surface by the transverse carpal ligament ${ }^{1)}$. Nine digital and thumb flexor tendons and the median nerve pass through this tunnel ${ }^{1)}$. Carpal tunnel syndrome (CTS) is a common, costly neuropathology caused by compression of the median nerve. The median nerve undergoes acute changes in response to repetitive manual jobs, which is further evidence of a potential causal relationship between repetitive manual jobs and median nerve injuries such as $\mathrm{CTS}^{2)}$. The prevalence of CTS is greater in workers who perform highly repetitive manual jobs ${ }^{3)}$. Overall, CTS is ranked sixth among recognized occupational diseases ${ }^{4}$.

Surgical treatment for CTS involves opening the carpal tunnel at the wrist. Currently, there are several non-surgical treatments for CTS, including non-steroidal anti-inflammatory drugs, injection of various medications, immobilization by splinting, rehabilitation modalities, and biofeedback devices $^{5,6)}$. While drugs, injections, and splinting relieve the symptoms of CTS, the long-term outcomes are poor ${ }^{1)}$. Therefore, we developed exercises for CTS and then investigated the effect of the release exercise and exercise position on CTS in a patient.

Corresponding author. Won-gyu Yoo (E-mail: won7y@inje. ac.kr)

C2015 The Society of Physical Therapy Science. Published by IPEC Inc. This is an open-access article distributed under the terms of the Creative Commons Attribution Non-Commercial No Derivatives (by-ncnd) License $<$ http://creativecommons.org/licenses/by-nc-nd/3.0/>

\section{SUBJECT AND METHODS}

A 40-year-old, right-hand-dominant man presented with pain and progressive tingling and numbness in his right hand. His symptoms worsened at night. The numbness increased when he used a computer at work. He had no systemic symptoms and no weakness or muscle wasting in either hand. There was no evidence of ulnar or radial nerve pathology. On physical examination, he had tingling and numbness over the radial three digits of both hands in the Tinel and Phalen's tests. The purpose and methods of the study were explained to the patient, who provided informed consent according to the principles of the Declaration of Helsinki.

To measure the amount of pressure applied by the therapist, a dolorimeter (Fabrication Enterprises, White Plains, NY, USA) pressure algometer was used to measure pressure pain. The dolorimeter consists of a metal probe that can measure pressures up to $20 \mathrm{lb}$ in $0.25-\mathrm{lb}$ increments. This was tested at a trigger point approximately $4 \mathrm{~cm}$ from the distal crease in the wrist, medial to the radioulnar joint ${ }^{7)}$. The participant reported when he felt that the pressure exerted by the algometer approximated the pressure exerted by the therapist. The study used three exercises. (1) In the release exercise: the subject elevated his hands overhead and then shook them for a few seconds and stretched his fingers wide apart. Then, he relaxed them, and then stretched them again. In addition, the subject's thumb was stretched by pulling it back gently, holding it, and then releasing it. (2) During the wrist flexor stretching exercise, the subject extended his arm in front of him with his with his palm up. Then, he flexed his wrist and, with his other hand, gently flexed his wrist farther until he felt a mild-to-moderate stretch in the forearm. This stretch was held for at least 30 seconds. (3) In the wrist 
extensor stretching exercise, the subject extended his arm in front him with the palm down. Then, he flexed his wrist and, with his other hand, gently extended his wrist farther until he felt a moderate stretch in his forearm. This stretch was held for at least 30 seconds.

In session 1, the subject performed exercises 2 and 3 in a standing position for 30 minutes each (total 60 minutes), once a day for 2 weeks. Then, in session 2, the subject performed all three exercises in the supine position for 20 minutes each (total $=60$ minutes), once a day for 2 weeks. Before and after each session, the therapist performed the Tinel and Phalen's tests 10 times each and measured the pressure pain.

\section{RESULTS}

Initially, the pressure pain threshold was $1.3 \mathrm{lb}$, Phalen's test was positive 8/10 times, and the Tinel sign was positive $7 / 10$ times. After session 1, the pressure pain threshold was $1.5 \mathrm{lb}$, Phalen's test was positive 7/10 times, and the Tinel sign was positive $7 / 10$ times. After session 2 , the pressure pain threshold was $2.5 \mathrm{lb}$, Phalen's test was positive $4 / 10$ times, and the Tinel sign was positive 3/10 times.

\section{DISCUSSION}

Carpal tunnel syndrome is caused by compression of the median nerve at the wrist, with symptoms typically confined to the lateral aspect of the palm, the thumb, and the next three fingers ${ }^{6}$. When nonsurgical treatment is indicated, corticosteroid injection into the carpal tunnel can be used to reduce pain and the tingling sensation. We developed exercises for CTS, and then investigated the effect of the release exercise and exercise position on CTS in a patient. Overall, the pressure pain threshold increased progressively after sessions 1 (standing position) and 2 (supine position, including the release exercise), while the fractions of positive Phalen's tests and Tinel signs decreased progressively. Therefore, CTS exercises in the supine position may elevate the wrist more, effectively reducing swelling in the carpal tunnel, thereby enabling the patient to exercise with less pain. Most patients tend to overlook the release exercise. These stretching exercises can relieve the symptoms of mild-to-moderate $\mathrm{CTS}^{1,6)}$. However, these exercises should be pain free. If a patient feels pain, numbness, or worse symptoms, it might have a negative effect on the performance of exercises for $\mathrm{CTS}^{1,6)}$. Our results indicate that the release exercise for CTS is very important for effective stretching. I recommend that patients perform the CTS exercises in the supine position, including the release exercise.

\section{REFERENCES}

1) Wilson JK, Sevier TL: A review of treatment for carpal tunnel syndrome. Disabil Rehabil, 2003, 25: 113-119. [Medline] [CrossRef]

2) Toosi KK, Impink BG, Baker NA, et al.: Effects of computer keyboarding on ultrasonographic measures of the median nerve. Am J Ind Med, 2011, 54: 826-833. [Medline] [CrossRef]

3) Rempel DM, Keir PJ, Bach JM: Effect of wrist posture on carpal tunnel pressure while typing. J Orthop Res, 2008, 26: 1269-1273. [Medline] [CrossRef]

4) Ibrahim I, Khan WS, Goddard N, et al.: Carpal tunnel syndrome: a review of the recent literature. Open Orthop J, 2012, 6: 69-76. [Medline] [CrossRef]

5) Yoo WG: Effect of a wrist motion storage biofeedback system (WMSBS) on wrist motion during keyboard typing work. J Phys Ther Sci, 2013, 25: 159-160. [CrossRef]

6) Neumann DA: Kinesiology of the musculoskeletal system: foundations for physical rehabilitation. St Louis: Mosby, 2009.

7) Elliott R, Burkett B: Massage therapy as an effective treatment for carpal tunnel syndrome. J Bodyw Mov Ther, 2013, 17: 332-338. [Medline] [CrossRef] 